\title{
Inhalts: Derjeichnis.
}

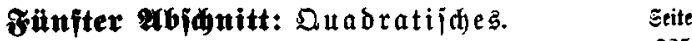

\$27. Tas Quabrieren und jeine $\mathfrak{U}$ múfehrung . . . . . . . 225

§ 28. Einjache quabratijaje (S)leidungen . . . . . . . . . 236

§ 29. Dritte Ertweiterung Desె Bahlengebiets (Эrrationale Bahlen), Redinen mit irrationalen פuabratwurzeln ...... 245

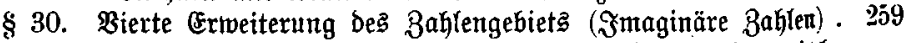

\$31. Duabratijde Bleidungen mit einer Unbefannten in arith= metifider Sprade, teifweife mit irrationalen und ima= gitnären $\mathfrak{B u r z}$ elut

§32. Eingefleidete quabratijo (S)eidungen mit einer lube= fannten

279

\$33. Quabratijde Bleidjungen mit mehreren Unbetannten in arithmetijuer Sprache

834. Eingefleibete quabratifhe Bireidungen mit mehreren llt= betannten

Gedister Mbidnitt: Die brei Dperationen britter Gtufe.

\$ 35. Botenzen mit ganzzahligen Exponenten . . . . . . . 303

\$36. \$urzzeln . . . . . . . . . . . . . . . . . 311

$\$ 37$. Fotenzen mit gebrodhenen anto irrationalen Erponenten. . 323

§ 38. Qogarithmen . . . . . . . . . . . . . . . . 328

$\S 39$. Sheometriidhe $\Re$ eiken und ihre Anwendungen, inşbejonbere auf bie Binfeszings und Rentenrednung. . . . . . . . 344

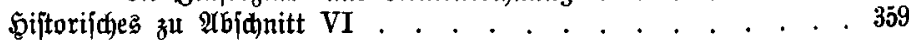

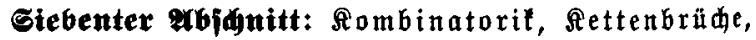
Diophantifae Brleidungen.

\& 40. Bermutationen . . . . . . . . . . . . . . 361

\$ 41. Rombinationen und Bariationen . . . . . . . . . . 364

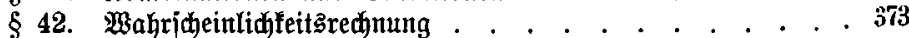

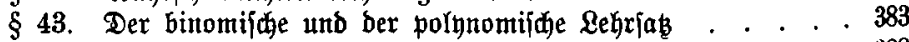

§ 44. Rettenbrüche . . . . . . . . . . . . . . . . 388

§ 45. Dioplantifäe Bleichungen . . . . . . . . . . . . . 399

Siftorifdes za Abfdinitt VII . . . . . . . . . . . . . . . 109

\section{Anbang:}

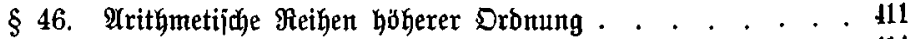

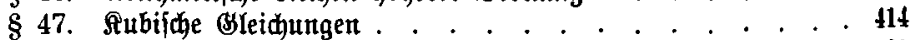

$\S$ 48. Funftionen, graphifiche Darftellungen, Marima und $\mathfrak{M}$ inima 420

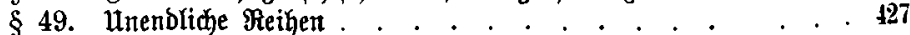

§ 50. SHeidhungen im allgemeinten . . . . . . . . . . . . . . . . $\quad \$ 39$

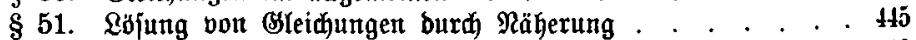

ફiftorijhes zum $\mathfrak{A}$ nhang . . . . . . . . . . . . . . . 418

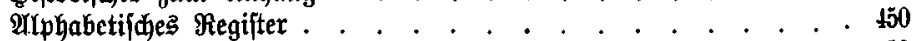

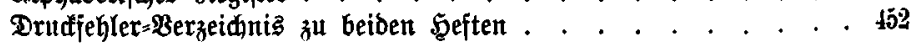




\section{Dnas erfte beft enthielt:}

Criter Orbjuntt: Einführung in bie arithmetifde Sprahe.

$\S$ 1. Die bier Species in arithmetijher Sprathe . . . . . . 1

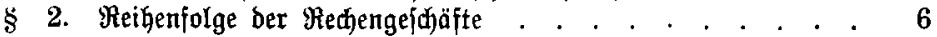

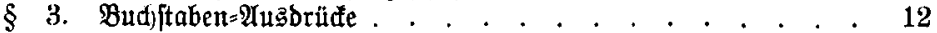

\$ 4. Budftaben=(Gleid)ungen . . . . . . . . . . . . . . . . . . 18

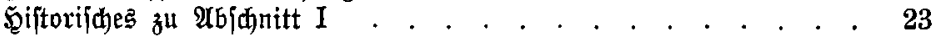

Bweiter Fbidutt: Dperationen erfter Stufe.

$\S$ 5. Begriff ber $3 \mathfrak{a h l}$. . . . . . . . . . . . . . . 24

$\S$ 6. Begriff ber $\mathfrak{2}$ bbition . . . . . . . . . . . . . . 31

§ 7. Begriff Der Subtraftion . . . . . . . . . . . . . 37

§ 8. Befebe ber erfter Stufe. . . . . . . . . . . . . . . . . . 42

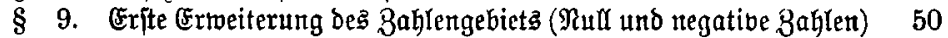

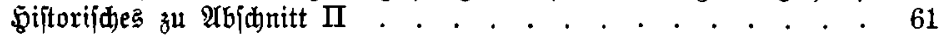

Dritter Fbinnitt: Operationen zreiter Stufe.

$\S 10$. Begriff ber Multiplifation . . . . . . . . . . . . 62

$\S 11$. Begriff der Dibifion . . . . . . . . . . . . . . 79

$\$ 12$. Befeze Der zmeiten Stufe . . . . . . . . . . . . . . . 88

§ 13. Bweite Crrweiterung beş Zahlengebietż (Gebrodhene Bahlen) . 103 Sifturifohes z̆ 2(bjめ)nitt III . . . . . . . . . . . . . . 123

Bierter Wbinitt: Anwendungen ber Befege ber Dperationen erfter und zwetter Stufe.

§ 14. Bidtige Berwandelungäformeln . . . . . . . . . . 124

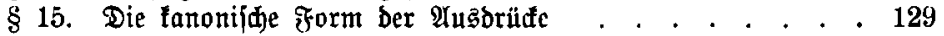

\$ 16. Proportionen . . . . . . . . . . . . . . . . 132

\$17. Figenidaften ber natürlident 8ahlen . . . . . . . . 140

§ 18. Bahrfojteme und Zahlzeiden . . . . . . . . . . . . . 149

§ 19. Dezimalbrü̆fe . . . . . . . . . . . . . . . . 154

$\S 20$. Máfe. . . . . . . . . . . . . . . . . . . 165

$\S 21$. (Kleidungen eriten Brabes mit einer unbefannten in arith= metifuer Spradje . . . . . . . . . . . . . 172

§22. Fingefleibete Bleidungen exften Brabes mit ciner un= befannten . . . . . . . . . . . . . . . . 182

\$ 23. Bleidungen erft n Srabes mit mekreren Unbefanten in arithmetifier Sprade . . . . . . . . . . . 196

§24. Fingelleibete (Jleidungen erften Brabes mit mehrerent unbefarnten................ . 207

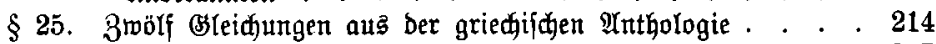

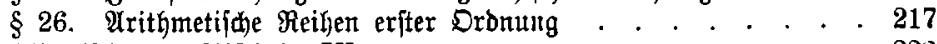

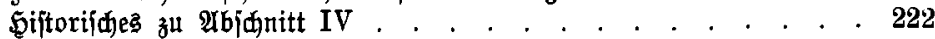

âlphabetifhes Regifter . . . . . . . . . . . . . . . . 223 